This is the accepted manuscript of the article, which has been published in

Information Processing and Management. 2020, 57(2), 102080.

https://doi.org/10.1016/j.ipm.2019.102080

\title{
Information needs of drug users on a local dark Web marketplace
}

Ari Haasio, J. Tuomas Harviainen, Reijo Savolainen

\section{ABSTRACT}

This study examines the nature of context-sensitive information needs by focusing on the articulations of need for disnormative information among drug users. To this end, the sample of 9300 messages posted to Sipulitori, a Finnish dark web site were examined by means of descriptive statistics and qualitative content analysis. The theoretical framework of the study was developed by drawing on Tom Wilson's idea of information need as a phenomenon fundamentally triggered by physiological, affective and cognitive factors indicating basic human needs. To examine the contextual features of needs for disnormative information, the study made use of Chatman's theory of information poverty characteristic of small worlds and Savolainen's model for way of life. The findings indicate that about $72 \%$ of the information need topics related to drugs dealt with the usage, availability and price of narcotics. The articulations of drug-related information needs reflected the users' ways of life dominated by the activities of buying, selling and using illegal narcotics. Drug-related information needs are typically triggered by physiological factors, because of the centrality of the physical dependence on drugs. Our study also revealed the simultaneous existence of physiological, affective and cognitive factors especially in messages in which the information need was articulated in greater detail.

Keywords: dark web; drugs; information need; information poverty; small world; way of life

\section{Introduction}

Information need is one of the most difficult and controversial topics in human information behaviour research. This difficulty stems from the fact that the generic concepts of information and need incorporate multiple meanings (Bates, 2017; Dover \& Joseph, 2008). Moreover, both concepts can be interpreted differently in diverse contexts. Therefore, to deepen our understanding of human information needs, it is necessary to delve into various contexts in which people living in personal situations articulate their information requests (Naumer \& Fisher, 2017). The present study contributes to context-sensitive research on information needs by concentrating on a particular group of people, that is, drug users seeking and sharing information on Sipulitori, ${ }^{1}$ a Finnish dark web marketplace. The dark web is a part of the Internet accessible only with specialized software, typically the Onion Router (Tor), which forwards messages by peeling off directing layers so that users supposedly cannot be identified (Gehl, 2016). This makes the dark web a useful environment for drug dealers, consumers of child pornography, and terrorists, but also for human rights activists, journalists and their confidential informants, and victims of spousal abuse looking for support.

Our investigation opens a new perspective on the study of information needs because the drug users represent people who often experience needs for disnormative information (Haasio, 2015a; 2015b). Norm is a philosophical and sociological concept with multiple meanings. In general, norms refer to actions over which people have control, and are supported by shared expectations about what should or should not be done in different types of social situations (Bicchieri, Muldoon \& Sontuoso, 2018). From this perspective, norms can be regarded as collective representations of acceptable group conduct as well as individual perceptions of particular group conduct (Lapinski \& Rimal, 2005).

\footnotetext{
${ }^{1}$ Sipulitori can be translated as "Onion Marketplace". The term onion (sipuli) is referred to technology used in Tor network (Tor = The Onion Router).
} 
Therefore, based on values, customs and traditions, norms represent individuals' basic knowledge of what others do and think that they should do. Normative sentences imply "ought-to" types of statements, usually dealing with the requirements of sincerity, justification, and honesty. Sentences containing normative information describes how people are expected to behave, if they take into account society's values, commonly accepted norms, rules of conduct and the requirements of laws. Conversely, disnormative information describes behaviour deviating from the above expectations and requirements. For example, the information offered by doctors about the risks of heroin use is normative in nature, while advising teenagers how to order heroin online is an example of offering disnormative information. Information concerning drugs, drug sales, and drug culture is disnormative in nature, as it goes strongly against prevailing societal norms.

Our study is also unique in that it examines information needs articulated in a non-public forum belonging to the dark web. Needs for disnormative information cannot always be expressed in public forums because messages containing information of this type may be removed by the moderators; besides, most of disnormative information sought by the users is unavailable through public channels. The Tor network enables the meeting of needs of this kind. Expressing a need for disnormative information requires anonymity, particularly if the user intentionally breaks the law. As the forums of the dark web enable anonymous use, needs for disnormative information can be expressed freely. So far, research on information needs dealing with illegal activities is extremely scarce. Information needs during terror attacks (Boyle et al., 2004; Haasio et al. 2018) and information needs among people experiencing domestic violence (Westbrook 2008; 2009) have been studied, but not from the perpetrator's point of view. Costello, Martin and Edwards Brinegar (2017) examined how people discuss the illicit use of marijuana and opioids on Reddit - a popular website. This study revealed that people often ask questions about how to use opioids safely; the users were also worried about the potential lethality of combinations of multiple drugs.

As the needs for disnormative information is a novel research topic, there are no conceptual frameworks directly applicable to the analysis of such needs. Therefore, we started by examining the potential of the generic models proposed by Taylor (1968) and Wilson (1981). Recently, there is a novel interest in Taylor's framework specifying four levels on which people articulate their information needs: visceral, conscious, formalized and compromised. Ruthven (2019) analysed the linguistic differences between conscious and formalized needs using postings to four major Internet discussion groups focused on the issues of diabetes, for example. The findings indicate that it is possible to differentiate levels of information need based on linguistic patterns and that the language used to express information needs can reflect an individual's understanding of their information problem. It is evident that Taylor's model would also be applicable to the analysis of information needs articulated by drug users. We may think that at the visceral level, the drug user has an unexpressed need that only reflects a vague feeling of dissatisfaction due to the lack of their daily drug dose, while at the conscious level the user recognizes a problem that requires attention, i.e., information on where to acquire the drug. Furthermore, the formalized need is expressed as a written request for the availability of a drug, posted to an online discussion forum, while the compromised need reflects the realistic opportunities for purchasing the drug from suppliers who may be accessed on the online forum.

However, as drug-related information needs are constituted by a complex set of physiological, affective and cognitive factors, we preferred another classic approach to human information needs introduced by Wilson (1981). He criticized the vague term "information need" and preferred an alternative approach by drawing on the findings of psychology. Wilson (1981) proposed that the study of factors triggering and driving information seeking should be based on the analysis of primary or basic human needs. First, there are physiological needs such as need for food, water and shelter. 
Second, affective needs deal with need for attainment and domination, while cognitive needs are constituted by the need to plan and learn, for example. Wilson (1981) contended that compared to basic needs, information needs are secondary in nature. Therefore, attention should be directed to primary needs by examining how their satisfaction may incorporate attempts to seek information. For example, hunger - a physiological need experienced by a person - gives rise to an information need, which manifests itself in questions such as "is there a restaurant at a walking distance?" Wilson (1981) emphasized that the satisfaction of physiological, affective and cognitive needs always occurs in environmental, social and cultural contexts. For example, easy access to a document can result in an immediate satisfaction of a cognitive need while a personal conflict with a former friend may form a barrier that hinders the meeting of such needs.

The present study takes a context-sensitive approach to the examination of drug-related needs for disnormative information. To achieve this, the main attention will be directed to the ways in which information needs articulated by the drug users are triggered by physiological, affective and cognitive factors. We assume that the articulation of drug-related information needs is affected by socio-cultural factors forming the everyday context of drug use. To conceptualize this particular context, we draw on the theories of information poverty and small world proposed by Chatman $(1996 ; 1999)$, because the drug users live in a social world restricted by the requirements of secrecy and the availability of narcotics. As drug use is often a major feature of daily life, the context of information seeking is also characterized by making use of Savolainen's (1995) model for way of life. Departing from the above ideas, the overall goal of the study is to find out what kind of information need topics are articulated by the drug users and how such needs are triggered by physiological, affective and cognitive factors.

The rest of the article is organized as follows. First, to create background, the nature of information needs is characterised, with a particular emphasis on information needs expressed in small world contexts. Thereafter, the conceptual framework, research questions and methodology will be specified, followed by the report of the empirical findings. The study concludes with the discussion of the main findings and their importance for information behaviour research.

\section{Literature review}

Since the 1960s, a number of studies have been conducted to examine the conceptual nature of information need (Taylor, 1968; Wilson, 1981; Derr, 1983; Cole, 2012; 2018; Savolainen, 2012; 2017). In addition, there is a variety of empirical investigations examining work-related information needs of diverse groups of people such as academic researchers (Herman, 2004), engineers (Bigdeli, 2007), physicians (Gorman, 1995), and literary critics (Chu, 1999). Moreover, there is a number of investigations focusing on non-work information needs articulated by people such as urban teenagers (Agosto \& Hughes-Hassel, 2006), cancer patients (Fourie \& Nesset, 2017), homeless parents (Hersberger, 2001), immigrants (Shoham \& Kaufman Strauss, 2008), prisoners (Rabina, Drabinski $\&$ Paradise, 2016) and first-time mothers (Ruthven, Buchanan \& Jardine, 2018). These investigations have identified a bewildering array of information need topics and the ways in which information needs are expressed in varying contexts of everyday life.

As the present study concentrates on information needs articulated in small world contexts, the rest of this section will review investigations relevant to this topic. In a series of ethnographic studies focusing on marginalized populations such as janitors, inhabitants of a retirement complex and female prisoners Chatman $(1991 ; 1992 ; 1996 ; 1999)$ discovered that the expression and development of information needs were largely influenced by social factors forming a "small world." It refers to social environments where individuals live and work, bound together by shared interests and expectations, and often economic status and geographic proximity as well. Within a small world, everyday 
information needs are affected by generally recognized norms and role expectations based on beliefs shared by members of the community. Therefore, information needs reported by the inhabitants of small world are also descriptive of their information worlds.

Chatman's (1996) theory of information poverty characterizes situations in which people living in a small world are unwilling to approach others in their usual social environments for much-needed information, hiding their information needs from potential sources of help. For example, among elderly women residing in a retirement complex, information poverty was determined by secrecy and self-protective behaviours in response to social norms (Chatman, 1992). Therefore, these norms dictate the types of information which may and may not be sought. The residents did not risk revealing certain health-information needs because of the potential negative impact on their lives. To elaborate further the nature of information poverty experienced in small world contexts, Chatman (1999) examined how female prisoners made attempts to seek information. The study revealed a strong connection between information need and the social context of the prisoners. Social norms determine what kind of questions (information needs) are regarded as meaningful: what to ask from fellow prisoners or staff and in which ways?

Chatman's $(1992 ; 1996 ; 1999)$ studies focused on people sharing the same physical space. Burnett and Jaeger (2008) demonstrated that small worlds can also exist in virtual spaces where people share similar values and interests (see also Burnett, Beasant \& Chatman, 2001; Burnett \& Buerkle, 2004; Haasio 2015b). Drawing on Chatman's ideas, Hasler, Buchanan and Ruthven (2014) examined the role of Internet groups in situations of information poverty. Through a qualitative content analysis of 200 posts across Internet groups, they identified a variety of information need topics expressed by people who feel they have no other sources of support available to them. The study demonstrated the existence health, well-being, social, and identity issues that are not only crucial to the lives of the people posting but which they are unwilling to risk revealing elsewhere. Overall, the findings of the above investigation highlight the importance of online forums providing an outlet for the expression of critical and hidden information needs that may be stigmatized if presented in face-to-face conversation.

Similarly, viewed from the perspective of small world, the needs for disnormative information expressed by drug users appear as semi-anonymous requests directed to the participants of online forums. The members of virtual small worlds of this type share the absolute requirement of secrecy which is reflected in the ways in which information needs are expressed. On the other hand, the formation of information needs among drug users is also affected by their way of life. Savolainen (1995, pp. 262-263) characterized way of life as "order of things," which is based on the choices that individuals make. "Things" stand for various activities taking place in the daily life world, including not only jobs but also voluntary activities such as hobbies; "order" refers to preferences given to these activities. Because the order of things is a relatively well-established constellation of work and nonwork activities taking place in a day or a week, this constellation is easily taken to be the most natural or normal way of organizing one's everyday life. Through their choices, individuals have practically engaged in a certain order of things, and it is in their own interest to adhere to that order as long as they find it meaningful.

The most central issues of way of life manifest themselves in the structure of the time budget, described as a relation between working and leisure time, models of consumption of goods and services, and nature of hobbies (Savolainen, 1995). The structure of the time budget reveals the proportions of time spent on various activities. Moreover, way of life is shaped by the habits of consumption indicating the share of money spent on the acquisition of various goods or services. The nature of hobbies is also indicative of the substance of way of life because the nature of hobbies 
informs us of the things that people find most pleasant. It is evident that a drug user's way of life is affected by factors such as these: time spent for the attempts to acquire daily doses of drug, as well as the time used for drug use, money spent for these purposes and the preference for seeking pleasure from the narcotics.

\section{Conceptual framework and research questions}

The studies reviewed above provided useful ideas for the specification of the conceptual framework and the formulation of research questions. Our study starts from the assumption that the articulation of needs for disnormative information dealing with drug use is a context-specific phenomenon. Articulation of needs for disnormative information is also affected by drug user's way of life preferring the seeking of pleasure from narcotics; this is also reflected in the consumption patterns of this group of people. Even though drug users do not form a relatively homogenous community similar to prisoners sharing a physical space, they nevertheless can be regarded as inhabitants of a virtual small world because their drug-related behaviour is restricted by the requirements of secrecy and the fear of being prosecuted for illegal possession and use of drugs. For the same reason, we may think that the inhabitants of virtual small worlds also include drug suppliers sharing information about the availability of narcotics. However, to strengthen the focus of the present study, the suppliers' information needs will not be examined, in cases where they were not also buyers.

Following Wilson's (1981) idea, it is assumed that information need is secondary in nature. Information need is triggered by three factors stemming from basic human needs: physiological, affective and cognitive. In the case of drug-related needs, the physiological component is based on the physical dependence in which the body adapts to the drug, requiring more of it to achieve a certain effect. The affective component deals with positive feelings such as the pleasure resulting in the successful acquisition of a drug dose or the fear of missing it due to lack of money. Finally, the cognitive component is based on the requirement of identifying useful sources of drug-related information or the requirement of evaluating the credibility such sources, for example, a drug dealer.

Drawing on the above framework, the present study addresses the following research questions.

- RQ1. What kind of information needs do drug users articulate in messages posted to a dark web forum?

- RQ2. In which ways are the drug users' way of life and the requirements of secrecy reflected in the articulations of information needs?

- RQ3. How are the drug-related needs for disnormative information triggered by physiological, affective and cognitive factors?

\section{Empirical data and methods}

The empirical data were collected in the beginning of January 2018 from Sipulitori (http://2i7aalqdpiuw36nu.onion/), a Finnish Tor site which at that time was one of the country's two largest drug trading websites, together with the cryptomarket Silkkitie (Nurmi et al., 2017). Sipulitori is one of three Tor sites founded on November 4, 2017, to replace Sipulikanava, a similar Tor site focusing on drug trade in Finland. Sipulikanava was closed by authorities three days before (Helsingin Sanomat Nov. 1, 2017). In addition to its major focus on illegal narcotics and other drugs, Sipulitori also has other criminal or semi-legal activities on its discussion forums. These include e.g., sales of stolen goods and weapons, and prostitution, but most of the discussion forums at Sipulitori concentrate on drug trading. Big cities and provinces each have their own forums, which are used for advertising and drug seeking. There are also separate discussion forums at Sipulitori for different 
topics concerning drug use, users' lifestyles, daily life, job seeking and advertising, and criminal activities.

Our research data consist of 9300 messages posted to Sipulitori. The site is based on anonymous messages combined with usernames from Wickr, the instant messaging system favored by Sipulitori users. This combination is important, because online drug sellers have to navigate the borderline between growing their market with public messages and the secrecy afforded by private messaging systems (Bakken \& Demant, 2019; Moyle et al., 2019). We downloaded our sample, when the website had been operating for almost two months. While we had observed the site from its inception, we chose this time a few days after New Year 2018 in order to obtain a sample that could be considered everyday traffic (as opposed to still containing e.g., "cold start" issues such as an atypical number of messages about whether the site itself could be trusted). The discussion threads were downloaded during a single night, using a manual copy-paste -technique, and put into Word documents.

There were 22 forums in Sipulitori in the beginning of 2018. Sipulitori preserves only the 150 most recent discussion threads on each of its forums. A discussion thread contains an opening message and the series of messages replying to it. The site automatically deletes older discussion threads and their messages. The sample thus contains all messages which existed on the site at the time of the sampling. We chose not to split the sample into smaller sub-samples, because we observed that the totality of the messages enables us to get a much more holistic picture of information needs and practices on the site than smaller samples confined to drug trading within particular geographical areas, for example. Importantly, the total sample enabled us to see, if drug users also posted on discussion threads about everyday life issues, frauds and thefts, for example.

In order to avoid ethical challenges in the analysis of the data, pictures ${ }^{2}$ inserted in the messages were excluded from the downloaded material. This was done as part of our ethical proofreading of the data. In ethical proofreading, the researcher assumes that informants can be identified from the published research. Therefore, he or she seeks to minimize any potential damage that could be done to them, even if it in fact is highly unlikely that they could be actually identified (Lee, 1993). We considered this especially important, since unlike in most other online environments, participant or even site owner consent could not be obtained due to the anonymity principles used on the site (Martin \& Christin, 2016; Ferguson, 2017). Furthermore, the site's users were in many cases involved in criminal activities that carry severe judicial penalties. The same message poster anonymity, however, enabled us to conform with the ethical guidelines established by the National Advisory Board on Research Ethics (2009) for research in the human and social sciences.

There are significant advantages to using online data in the examination of information needs (Ruthven, 2019, pp. 80-81). Firstly, the needs are expressed as they are felt. People post on what is of current concern, generally as narratives, rather than later reflections on experiences. This means the messages are 'immediate' in providing the context of a person thinking through their situation. Secondly, it is possible to deal with many more people and their stories than is typically reported through interviews. Thirdly, the information needs are described as written statements of a situation and/or need that can be analysed textually to uncover patterns within the texts. However, there are disadvantages, too. Unlike surveys or interviews, researchers cannot ask specifying questions of the participants or clarify the meanings of individual questions. Therefore, the study can only examine what is expressed in posted messages rather than the totality of what is felt or experienced by the online contributors.

\footnotetext{
${ }^{2}$ Most of the pictures were about drugs and their purpose was to convince the buyers about the quality of the drugs.
} 
Both quantitative and qualitative content analysis methods were used on the data. In order to prepare the coding process, first and second author read the messages several times. At this phase, particular attention was devoted to sentences incorporating interrogatives such as "what", "how", "where" and "when", as well as expressions like "does somebody know" because they are indicative of needs for information. Thereafter, a preliminary codebook was developed by inductively identifying from the data four main categories $\mathrm{A}-\mathrm{D}(\mathrm{A}=$ information needs, $\mathrm{B}=$ information sharing, $\mathrm{C}=$ marketing, and $\mathrm{D}=$ identity-related information), each of which divides into diverse 18 subcategories (e.g., drug trading, drug use, hormones, lifestyle, sex). As a result, all the messages were classified into one or more 72 categories (many of which dealt with processes other than information needs, due to which we are not presenting all of them in this article). One message could belong to several categories (e.g., information need formulated and information shared about something in the same message; information sharing and marketing at the same time). As all the 9300 messages were coded manually by first and second author, the process was time-consuming. However, as noted above, the coding of the total sample enabled a significantly more comprehensive picture of the information needs expressed by the drug users. After coding there were 72 subcategories, of which 18 (A1-A18) dealt with information needs. Only categories A1-A18 were taken into analysis:

A1 Drug purchase, availability and price

A2 Using drugs

A3 Effects of drugs

A4 Growing \& manufacturing drugs

A5 Quality of drugs

A6 Trust in drug sales

A7 Hormones

A8 Fraud

A9 Weaponry

A10 Sex \& prostitution

A11 Security \& debt collection

A12 Hacking

A13 Police, officials \& legal questions

A14 Everyday life

A15 Tor-network

A16 Jobs, working \& earning money

A17 Trolling \& provocation

A18 Identity

The analysis was confined to messages indicating a direct information: explicitly indicating topics of information needs expressed by drug users. Individual information need topics such as Effects of drugs and Identity were coded when they appeared for the first time in a message; other instances of the same information need topic were simply ignored. The information needs expressed by drug suppliers were excluded from the analysis. However, such needs were examined in cases in which a seller was also a buyer, or offered a trade. In fact, this category covered a considerable number of active posters who first appeared as buyers in the "mass quantity sales" section, and then as sellers (and also often buyers) in one or more local sections.

The coding was then refined inductively, by identifying diverse information need topics expressed in the messages. This effort resulted in the identification of eight categories: drugs and hormones, sex, information and communication technology (ICT), selling/buying goods \& earning money, identity, safety, trolls \& provocation, and life management. Moreover, seven categories of drug-related information need topics were identified: drug purchase, availability and price, usage, effects of drugs, manufacture or growing of drugs, quality of drugs, trust, and hormones. As the expressions of drug- 
related information needs are affected by the requirements of secrecy and the drug user's way of life, the research data were coded by identifying phrases which indicate the risks and consequences of illegal activity, living habits and consumption patterns, for example.

The coding was finalized by concentrating on messages indicative of the physiological, affective and cognitive triggers of drug-related information needs. Again, the above factors were identified inductively from the data. A physiological factor describes the physical dependence on drug, that is, condition caused by chronic use of a tolerance forming drug, in which abrupt or gradual drug withdrawal causes unpleasant physical symptoms. Physiological factor giving rise to information need is exemplified by the following extract: "I buy all kinds of oxycodone products (Oxynorm, Oxycontin, Targiniq, Oxycodone). I pay well, very acute need! Also all other "harder" opioids are OK!". Affective factor describes an appraisal of an object based on the experience of emotion or feeling, positive or negative. An example of the affective factor is: "The feeling when you've been high for two weeks, smoked $15 \mathrm{~g}$ weed and tomorrow you gotta go to work. Do I have to get some speed or does one have enough guts?" Finally, cognitive factor describes the process of acquiring knowledge and understanding through thought. For example, asking "If you've bumped into crystal meth in Finnish drug market, what has been the price?" indicates the existence of a cognitive factor triggering an information need.

An individual category, that is, physiological (P), affective $(\mathrm{A})$ or cognitive $(\mathrm{C})$ trigger was coded when it appeared for the first time within a message; other instances of the same trigger were ignored. Particularly in the case of short messages, the coding was simple and the trigger could be clearly identified as either physiological, affective or cognitive. In the case of intertwined (hybrid) triggers, the coding was based on the identification of diverse combinations of triggers, more precisely, P \& A, P \& C, A \& C and P \& A \& C, depending on the content of the message.

During the various phases of the coding process, the intercoder reliability was checked by comparing the categorizations made by the first and second author. Whenever differences in classification were found, they were discussed and a decision of the classification of every message in those cases was made together, until the two manual coding sets were completely identical.

In order to answer the first research question, a statistical data set was created. It contains messages that were coded as information need topics (categories A 1-18). They were scrutinized by means of descriptive statistical analysis by calculating percentage distributions. In the next phase, qualitative analysis was conducted to answer research questions 2 and 3. More specifically, qualitative content analysis was conducted by drawing on the constant comparative approach (Tesch, 1990, 96). To this end, the method of comparing and contrasting was used summarizing the content of each category, as well as finding similarities and differences between the categories. First, attention was directed to messages indicative of the drug users' way of life and the requirements of secrecy: how were they reflected in the articulations of information needs? The analysis was finalized by focusing on the scrutiny of the physiological, affective and cognitive factors giving rise to drug-related information needs. The final phase also entailed the identification of connections between the above categories because they often appear together. For example, a physiological factor such as addiction may be accompanied by a cognitive factor like uncertainty about the availability of a drug.

\section{Findings}

\subsection{Information need topics}


Out of 9300 messages examined in the present study, the number of messages indicating the existence of one or information need topics was 2329 , that is, $25 \%$ of all messages. As an individual message may express more than one information need topic, the number of codes indicating such topics was higher than the number of messages with information needs, that is, 2788. In the quantitative analysis, the 18 subcategories of information needs specified above were collapsed into broader categories if they represented similar topics. As a result, eight categories of information need topics were formed. The distribution of such topics is presented in Table 1.

The empirical analysis identified eight main categories of information need topics (see Table 1). Most of them concerned drugs and hormones $(54.8 \%)$. This category entails all information needs concerning illegal drugs, misuse of the prescription drugs and hormones. Two other significant categories were information needs concerning the information technology (12.9\%) and selling/buying goods \& earning money $(12.4 \%)$. Other categories recognized were sex $(6.9 \%)$, identity $(5.2 \%)$, safety $(3.6 \%)$, life management $(2.9 \%)$ and trolling \& provocation $(1.3 \%)$.

Table 1. Information need topics.

\begin{tabular}{|l|l|l|}
\hline Information need topics & $\mathbf{n}$ & $\mathbf{\%}$ \\
\hline Drugs, hormones & 1528 & 54.8 \\
\hline ICT & 359 & 12.9 \\
\hline Selling/buying goods \& earning money & 346 & 12.4 \\
\hline Sex & 193 & 6.9 \\
\hline Identity & 144 & 5.2 \\
\hline Safety & 100 & 3.6 \\
\hline Life management & 81 & 2.9 \\
\hline Trolls and provocation & 37 & 1.3 \\
\hline TOTAL & $\mathbf{2 7 8 8}$ & $\mathbf{1 0 0}$ \\
\hline
\end{tabular}

Sipulitori is mainly a network concentrated drugs and everything what is associated with them. Information needs that did not directly deal with drug sales or usage, however, were indirectly linked to drug culture.

For example, the information needs concerning Information and Communication Technologies (ICT) $(12.9 \%)$ were mostly questions about the usage of tor network and hacking. They were also often related to questions of safety $(3.6 \%)$, because the fear of authorities and frauds was dominating many discussions about different topics.

Is there any crypted chat for PC?

In search for a pro who can unlock Macbook Pro 2016 iCloud

How to hack Facebook account or e-mail?

For example, hacking was often related to earning money and spending it to drugs. To finance their drug usage many participants sold e.g., computers, cell phones, ID's, bicycles and other valuable items, which were often stolen. In these cases, the information needs concerned either availability of certain goods or the need for buying goods that were for sale $(12.4 \%)$. Information needs related to trading stolen goods, and ID's were typical. In most cases people wanted to sell certain goods and the information need concerned potential buyers and their willingness to buy products for sale. 
Selling goods is one way to finance the drug abuse. Some of the information needs were related to searching a job, which in this case meant some illegal work like selling drugs.

Need for something to sell. Pills, weed, XTC. I have experience.

Honest, young female criminal in search of jobs.

Jobs as dealers, companionship in frauds, and debt collection were also offered in the forum.

In search of guy who has clear credit history or can steal e.g. shoes, clothes, electronics, e.g. laptops. I will pay 100-200 €.

In search of dealers! I need some permanent guys to get metamphetamine to streets in small amouts (10-20 g) at a time. I suppose you know the basics and are Finnish, over 18 yrs and don't use or dilute the product (recreational use OK)

The information needs about sex (6.9\%) were mostly about either selling sex ('sponsorship') or seeking for sexual companionship. Interestingly, in most cases such as these, money was not wanted, and using drugs was an important part of "chilling". Sex services were often exchanged to drugs or both money and drugs. In many cases, women were offering sex, but they also wanted to use drugs together, instead of looking for money. Sometimes, drug using companionship was even sought with no sexual intentions.

Any guys who'd like to smoke weed and have sex? Woman in the middle of Helsinki wants to chill. Sponsorship would be nice.

In search of conversation company at least in the beginning, later when it is warmer sitting in a park is OK. I'm 20 yrs old guy from Lahti. I use drugs randomly in recreational use. Smoking buddy would be nice as far as chemistry is right.

Of all information needs, 5.2 percent concerned a drug user's identity. They were often related to trust - when doing drug deals confidence between seller and buyer seemed to be very important. Cover operations by police were feared and especially vendors' reliability was often questioned. There were also many racist messages, about not trusting immigrants or members of minority groups in the drug business.

\subsection{Drug-related information need topics}

The fact that most of the information needs dealt with drugs was predictable because Sipulitori was founded to enable the continuation of domestic drug trade in Finland when Sipulikanava was closed. To refine the picture of information need topics, the category of drugs and hormones $(n=1528)$ was further divided into seven subcategories presented in Table 2.

Table 2. Drug-related information needs.

\begin{tabular}{|l|l|}
\hline Information needs & \% \\
\hline Drug purchase, availability and price & 71.8 \\
\hline Trust & 7.3 \\
\hline Usage & 5.9 \\
\hline
\end{tabular}




\begin{tabular}{|l|l|}
\hline Effects of drugs & 5.4 \\
\hline Hormones & 4.7 \\
\hline Quality of drugs & 3.1 \\
\hline Manufacture or growing of drugs & 1.8 \\
\hline TOTAL $(\mathrm{n}=1528)$ & 100 \\
\hline
\end{tabular}

The largest subcategory was information needs associated with drug purchase, availability and price $(71.8 \%)$. These three factors were so closely intertwined that they could not be separated into subcategories, even though not every message in the data set contained all three. The availability of certain drugs was often asked as well as the price. Many buyers also indicated how much money they were able to spend for certain drug. In many cases, the need of certain drug was acute and buyers used expressions like "quickly", "asap" or "today".

Trust (7.3\%) was in an important role of recognized information needs. Hoaxes, robberies and frauds are always possible during the drug deal, as one cannot go and complain to the authorities if one is cheated or robbed. The issues of trust were also affected by the fact that drug users and sellers with different interests share the same online forum. Because of that, the reliability of dealers who were identified by their Wickr aliases was often inquired (Harviainen, Haasio \& Hämäläinen, in press). This connects to a wider trend, created by the ways in which instant messengers have been decoupled from the social media to which they were earlier connected (e.g., Nieborg \& Helmond, 2018), but the disnormative nature of drug trading sites accentuates such situations.

Sipulitori administrator founded a separate Tor site called Rottaverkko ['RatNet'] to systematically collect feedback from both drug vendors and buyers and especially find out which vendors are not trustworthy. So far, that site has not served this purpose well, due to the lack and inactivity of users (Harviainen, Haasio \& Hämäläinen, in press). Nevertheless, the existence of the RatNet highlights the importance of trust for selling and buying drugs. Robberies and hoaxes are common in drug trafficking and before people do business with a new vendor, they ask experiences from other users. Many buyers were afraid of "rats", that is, people who tried to rob the buyer or sold inferior products. Also, fear of the police was manifested in some information needs. This explains why the information needs concerning especially vendors, their reliability, and the quality of their products occupy a central role in Sipulitori.

Trust was often connected to the questions of quality (3.1\%) which also is positively associated with the reliability of dealer. Those dealers whose drugs were of good quality and who kept their promises were considered as trustworthy. Buyers wanted to know the quality of drugs and also the vendor's reputation as a seller.

Has anyone bought anything from Päälääkäri ['Head Doctor'] and what kind of experiences do you have? No negative feedback here, but still suspicious. He has cheap Subutex $(187 € /$ disc $)$, but do I dare to buy? ${ }^{3}$

Who sells the best quality speed here in Sipulitori?

Information needs concerning the use of drugs $(5.9 \%)$ were mostly questions about the cross effect of different drugs, drugs and alcohol or the combined effect of prescription drugs. Many of the information needs were also about the dosage of drugs. Especially those users who did not have long

${ }^{3}$ All messages cited in this article were translated from Finnish to English by authors. 
experience of a certain drug asked advice from more experienced users to avoid an overdose or to get "kicks" good enough.

How much oxycodone you've taken in a day? I've taken $120 \mathrm{mg}$ and I wonder can I take $20 \mathrm{mg}$ more?

How many milligrams of Tramal [tramadol hydrochloride] should I take to get good kicks?

How much beer you can drink so it doesn't decrease the effect of weed?

While using drugs, the effect of different drugs was asked (5.4\%). In this category, people discussed the tolerance levels they had, and experiences from "trips". Similarly, the health effects were asked.

Is it true that THC is less harmful to your brains if you eat it instead of smoking it? And is flower less harmful than hash just because of the lower THC content?

This message implicates also the concern of own health and drug abuse's effect to it. However, in most cases the information needs about the health effects concerned overdoses, and how to avoid them.

A category clearly distinct from others was information needs concerning hormones $(4.7 \%)$. Athletes and bodybuilders purchase hormones via Tor network, but they do not necessarily use narcotics of any kind. Many vendors were also specialists who just sold hormones, but not any illegal drugs. Only a few of them sold both drugs and hormones. Information needs in this category were mostly about the availability of different types of hormones.

Surprisingly, advice how to grow drug plants, e.g., hemp, or to manufacture drugs via chemistry seldom appeared among the information need topics $(1.8 \%)$. Some advice was asked about the lights and watering, but the information needs were primarily dealing with the sales and usage of drugs, not in making or cultivating them.

\subsection{Information needs as expressions of way of life}

Criminal activities are predominant in the information needs present in our material. Almost all information needs deal with illegal activities, which could not be expressed in an open network. Therefore, the "small world" of Sipulitori's users differs from other "small worlds" characteristic of other groups such as cancer patients or video gamers. In the latter cases, the common denominator is not illegal, and an information seeking process can be open in its nature.

The qualitative analysis revealed that the articulations of information needs are indicative of the drug user's way of life. A related study (Harviainen, Haasio \& Hämäläinen, in press) found that the contributors to the discussions occurring in Sipulitori are mostly 1) recreational users (people who use drugs only occasionally), 2) daily users (people who regularly use drugs and are likely addicted to them), and at the bottom of the site's hierarchy, 3) "junkies" ("nisti" or "narkkari" in Finnish, derogatively used by numerous posters on the forum to denote people whose life is dominated by their addiction, making them untrustworthy), and 4) sellers, who on Sipulitori largely overlap with the other three categories, as the site appears to host very few sellers who do not themselves use drugs. Sipulitori was especially used by people on the lower income scale of the economic spectrum of drug users. Stereotypical wealthy users of expensive drugs such as cocaine are largely non-present on the 
forum because they have their own networks elsewhere. The above study identified three types of users. Recreational users told that they have a daily job, as did some daily users. Junkies' way of life was more or less characterized by buying, selling and using drugs, and as a whole their lifestyle was very drug-centered. The junkies also used harder drugs like opioids and injected drugs and they were living as outsiders according to their own stories in the forum, because they did not work or study. This is in line with Agar's (e.g., 1996) observation that not all drug addicts fit the concept of a "junkie" and may organize their lives and drug use very differently.

Some of the aliases used in Wickr (e.g., "narcinalku" = "beginner junkie") supported that observation, too. The distinction between user types was made clear in Sipulitori's discussions (Harviainen, Haasio \& Hämäläinen, in press), where especially "junkies" have very low status. The following example shows how a recreational user makes a clear difference to junkies who are badly dependent on drugs:

Only weak people become junkies. I'm a recreational user and done it for five years. Sometimes I've used drugs intravenous and never suffered withdrawal symptoms. GET A JOB AND ENJOY DRUGS DURING THE WEEKENDS, FOR GOD*S SAKE!

[Any w]oman in Oulu [interested in] a meth fuck. I Am no sleazyjunkie ... picture available!!

Peer information can be seen here as an important role in satisfaction of the information needs. Experience was highly appreciated especially in those information needs which concerned drug trade and usage. Among certain small groups like gang members or junkies, the information shared by another person living in a same kind of a life situation, having a similar lifestyle or sharing similar experiences, is highly appreciated (see Haasio 2015b). In this case, for example, information about the effects of drug use, growing the drug plants, or drug dosage peer information was in a big role and other drug users' experiences were trusted. On the other hand, the information needs were also of the kind that cannot be satisfied by consulting publicly available documents. This is mainly due to the fact that many information needs dealt with illegal activities. The importance of peer information can also be seen in questions dealing with the reliability of vendors. On the other hand, due to the illegal or criminal nature of drug trading, peer information is the only way to get information about these topics

The requests for disnormative information are indicative of the way of life because using drugs can be seen as the most predominant thing in everyday life. Because of this, the drug-centered way or life and lifestyle not just dictates the rhythm of daily life, but also determines the information needs experienced by the users. The effect of the way of life on the expressions of information need can be recognized in various areas. Earning money by means of criminal activities (frauds, selling stolen goods or drugs), and having sex and using drugs at the same time, are good examples. Everything is done to finance and make the drug use possible. Drug use motivated by social addiction is strongly connected to way of life and users' social life (Best et al., 2015). Drug use is for many people on Sipulitori a social activity, a part of their everyday life. It can also occur on a non-daily basis, as recreational use that is typical for spare time, such as weekends and holidays. This can be verified in our research data: some of the messages were from New Year 2018 or just before it, and celebration created a demand of drugs in cities, as well as in Lappish skiing resorts, for example. On the other hand, some of the buyers also mentioned that they are recreational users, when describing their usage habits.

\subsection{Physiological, affective and cognitive triggers of information needs}


Following the idea of Wilson (1981), three main factors triggering the information needs were examined: 1) physiological trigger, 2) cognitive trigger and 3) affective trigger.

\subsubsection{Physiological trigger}

Drug use can cause either physical or psychological addiction depending on a drug. Addiction can be defined as compulsive action despite the consequences it causes (Hyman, 2005). Drugs can cause physical addiction, which occurs as tolerance increases and a user has to get more drugs to prevent withdrawal symptoms. Psychological addiction is a compulsive need to act in a particular way in a particular situation. Both types of addiction are also accompanied by the enjoyment of drug use based on past experience. According to Wise and Koob (2014), addiction begins with the formation of habits through positive reinforcement. Drug-opposite physiological responses often establish the conditions for negative reinforcement to come into play at a time when tolerance, in the form of increasing reward thresholds, appears to develop into positive reinforcement. Some drugs, like cannabis and amphetamine, may quite rapidly cause a strong psychological addiction and also the tolerance becomes higher (Barceloux, 2012; Airaksinen, MacDonald \& Korpi, 2014). Several studies made about drug addiction point out that the usage of opioids, for example, can result in habitual and eventually compulsive use (Barceloux, 2012; Koob, Arends \& Le Moal, 2014; Kalso, 2017).

The qualitative analysis of the messages posted by the drug users revealed that a physiological trigger was mainly caused by the physical addiction to drugs:

Three days being high with speed, hash and pills will end now. What to do?

Could I get a link to Onion Road? I can’t find. I can't find one. I need drugs. Today For my withdrawal symptoms.

The above messages exemplify typical cases in which a user is physically dependent on drugs and that in the final end, the dependency triggers the information need dealing with the availability of a drug. The physiological trigger affects especially information needs which concern amphetamine and other drugs causing physiological dependence. Overall, the empirical analysis revealed that physiological drug dependence is associated especially in requests concerning availability of drugs. In particular, withdrawal symptoms caused need to get a new dose of drugs. Especially drugs such as opioids in which physiological addiction and tolerance are easily developed were needed "quickly" or "immediately" in some messages.

Physiological triggers were also observed in information needs concerning sex. In some cases, different kind of sexual needs were expressed and in that context the information needs concerned the possibility to find companion to fulfil one's sexual desires.

\subsubsection{Cognitive trigger}

The term cognition is generally used to describe the intellectual or perceptual processes occurring within the mind when an individual analyses and interprets both the world around herself and her own thoughts and actions (Petri \& Govern, 2004, p. 248). From this perspective, cognitive factors can be defined as a group of mental processes that includes attention, memory, and activities such as producing and understanding language, learning, reasoning, analyzing, concluding, planning, evaluating, problem solving and decision making (Sternberg, 2009). 
Cognitive triggers were identified particularly in information needs dealing with Tor-network and information technology, making frauds and the reliability of different drug vendors. Similarly, when growing the hemp plants or contemplating the dosage, the cognitive trigger was clearly noticeable.

Could someone tell me more about PGP? How does it work?

Why I can't get rid of utorrent and how can I format my computer? Do I really have to take it to some store and how much would it cost?

Cognitive triggers existed in all categories and they were expressed as clear questions regarding the topic of its forums.

\subsubsection{Affective trigger}

Emotions can motivate information seeking in various ways: they may start, expand, limit, or terminate the information-seeking process, or they lead to information avoidance. (Savolainen, 2014). In the context of drug usage, fear is an important affective factor giving rise to information needs. Because the buyers are afraid of robberies, hoaxes and scams, as well as police, fear is a strong emotion triggering information needs. Drug usage is motivated among other things by the positive user experiences and a feeling of pleasure (Julien, Advokat \& Comaty, 2011; Wise \& Koob, 2014).

We found that the positive psychological experiences and feelings may function as affective triggers of information needs. Especially information needs dealing with the ethnic background or trust of the vendor incorporated the affective features. Moreover, the discussions about vendor's reliability were based on affective reasons. In many cases, the fear of authorities and the reliability of other sellers gave rise to information needs, which can be understood as affective. A good example of fear can be found from the message:

How have people robbed you, or been trying to rob you?

The former example shows how the trigger of information need is based on the fear of robberies in the drug trade. Affective concerns such as these were frequent in the messages posted by the drug users. Sometimes, the participants also expressed positive feelings. The need for tenderness exemplifies an information need whose trigger is affective in nature:

All I want is a woman with whom to be with and enjoy her laying next to me in the sun until midday.

\subsection{Hybrid triggers}

The qualitative analysis revealed that information needs may also be triggered by a combination of physiological, affective and cognitive factors, thus forming "hybrid triggers". The following example illustrates triggers of this type.

I took $400 \mathrm{mg}$ of Tramadol and after two hours $200 \mathrm{mg}$ more and I don't feel any effects and don't have any tolerance. What is wrong because I don't get high?

In this example, the trigger consists of a physiological element (need to get high) and cognitive element (why the drug does not have the impact that it should?). Both cognitive and physiological element can also be identified in the following expression of information need: 
Do stimulants weaken the peripheral blood circulation? And if so is there any medication which would improve the peripheral blood circulation? Opioids?

The information need is triggered by a physiological problem, but there is also a cognitive element when asking about opioids' impact to the peripheral blood circulation. The following case illustrated the hybrid of cognitive and affective factors.

Surespot? ${ }^{4}$ Does anyone have any experience with this application? I've understood that it [Surespot] is much safer than Wickr - or is it?

The person in need of information has a fear (affective element) that his communication via Wickr can be traced. Now he wants to know (cognitive element) facts about the security of Surespot application, as compared to Wickr, the messaging system commonly used for communication in drug deals on Sipulitori.

Information needs can also be trigged by both affective and physiological elements. For example, in suicidal messages they are combined when the information needs concerns suicide as an alternative. The presence of affective trigger is indicated by the person's feeling of despair giving rise to question whether suicide would be the only way to get rid of mental anguish. A physiological element is also there because the person may experience his physical condition so bad that getting better is no longer possible.

In some cases, all three factors, physiological, affective and cognitive giving rise to an information need were identifiable from the messages posted by drug users.

Exclusion breaks me down. No work or place to study. No girlfriend. There are friends, but there is nothing to do with them when using drugs, so it's better to be clear on your own. I would just like to have a woman next door to bed in the middle of noon. But I can't find it by hiding at home. Fortunately, with frauds, money is slowly accruing ... Even though I could earn as much having a job and working. How to recover from exclusion?

The factors triggering the need for information is a feeling loneliness, physiological and emotional need for proximity, and in addition, sex. Moreover, the cognitive factor can be identified when the person asks to possible treatments for recovering the exclusion.

\section{Discussion}

The present study contributed to research on context-sensitive information needs by examining a unique topic, that is, how drug users articulate needs for disnormative information in dark web forums. The research context is novel because prior studies of drug-related information needs have focused on information requests presented in public online environments such as Reddit (Costello et al., 2017). Our study also contributed to theoretical issues of information behaviour research by demonstrating that Wilson's (1981) idea of information need as a secondary entity opens a promising perspective on the elaboration of the factors giving rise to information seeking. This is because information need is not approached as a vague composite term suggesting a connection between information and need. The discriminatory power of the construct of information need is increased if

\footnotetext{
${ }^{4}$ Surespot is an encrypted messenger. See https://www.surespot.me/.
} 
it is approached more analytically by differentiating its psychological, affective and cognitive components. The above approach also enables a more dynamic picture of information need as a phenomenon shaping through the interaction physiological, affective and cognitive factors.

The analysis of the sample of 9300 messages posted to the dark web forums revealed that the users' information need topics revolve around drugs, even in the case of self-described recreational users. Almost $55 \%$ of the articulations of information needs were explicitly dealing with drugs and hormones. Moreover, many of the information need topics such as ICT and sex were indirectly related to the efforts to sell or purchase drugs. Almost $72 \%$ of the information need topics directly related to drugs dealt with the usage, availability and price of narcotics. The articulations of drug-related information needs reflected the users' ways of life dominated by the activities of buying, selling and using illegal narcotics.

This feature is important for the study of information needs, because the drug-trading nature of the site allows us to look into disnormative information needs in a context specifically dedicated to them. The dedication, plus the sense of being members of a strictly anonymous and secretive community, appears to have granted Sipulitori's users the possibility to openly discuss their information needs and ways of life. Our findings support Chatman's $(1991 ; 1996 ; 1999)$ conclusions about the preference for seeking information from peers, that is, inhabitants of a small world having similar experiences. The preference for requesting information from other drug users in Tor forums is also due to the fact that disnormative information of this type tend to be unavailable in public websites. Hasler et al. (2014) drew a similar conclusion in a study focusing on Internet groups in situations of information poverty by showing that online forums provide an outlet for the expression of critical and hidden information needs that may be stigmatized if presented in face-to-face conversation. It is typical for drug users to seek for the kind of disnormative information that makes illegal activities possible. In previous studies, the aspect of illegality has not been the dominant reason for information seeking. This aspect of illegality places demands for the information seeking environment and need of trust. Seeking information from Sipulitori is natural because the information needed for illegal activities needs to be sought from the channel where the community accepts this kind of behaviour. The community of drug users protects its own members from law and enforcement's officers.

According to Chatman (1996) the main characteristics in the the information world of poor people are deception, secrecy, risk taking, and situational relevance. All these elements can be found from the discussions of Sipulitori. Especially secrecy is in an important role because of the nature of subject. Illegality requires secrecy. The influence of this subject, however, would require an article of its own.

Prior studies on information needs have concentrated on the cognitive component of information requests articulated in work-related and learning contexts in particular (e.g., Juric, 2017; Miranda \& Tarapanoff, 2008). On the other hand, there is a paucity of investigations examining the affective and physiological factors giving rise to information needs. The factors have primarily been examined in health-related contexts by analysing the role of emotional cues in sense-making among kidney patients (Godbold, 2013; for an overview, see Savolainen, 2014). Fourie and Nesset (2017) examined the nature of physiological trigger while reviewing studies on cancer pain and information-related needs. Our study pioneered by analyzing diverse combinations of physiological, affective and cognitive factors. Drug-related information needs are typically triggered by physiological factors because of the centrality of the physical dependence on drugs. Affective and/or cognitive factors tend to be secondary in this regard. Affective factor gives an emotional tone to the physiological trigger, for example, by describing the desperate nature of the need felt by the user, while the cognitive factor indicates how the user evaluates the price level of the desired drug dose, for example. Our study also 
revealed the simultaneous existence of physiological, affective and cognitive factors especially in messages in which the information need was articulated in greater detail.

Physiological, affective and cognitive factors may not merely function as triggers initiating the information-seeking process. Savolainen (2017) proposed that information needs can be also approached as drivers that keep the information-seeking process in motion. In the case of drug addiction, physiological reasons (addiction, withdrawal symptoms) are the foremost drivers that cause an ongoing information-seeking process. This is typical especially to users who prefer opioids and have high tolerance levels. In addiction, drugs are needed on a daily basis. Because of this, information about the availability and price level of drugs has to be procured continuously. Dependency therefore acts as a catalyst for continuous information seeking, and makes sure the user experiences the same information need on a daily basis. The fulfillment of the need, however, may be difficult, as it is influenced by a highly fluctuating context, in which dealers may end up arrested, drug qualities vary, sellers can be identified solely by their Wickr names, and even the trading sites themselves may end up being closed without warning.

Due to its explorative nature, the present study is limited in that the focus was directed on a specific group of people articulating drug-related needs for disnormative information in dark web forums. Therefore, the findings cannot be generalized to concern the motivators for seeking disnormative information about other topics. Given the novelty of the research topic, there is a number of issues requiring further research. One of the research tasks is to compare the articulations of need for disnormative information in dark web and open web forums (e.g., Costello et al., 2017). As to the particular features of drug-related information needs, more comparative research is needed to examine the nature of physiological, affective and cognitive factors, as well as their interaction. From this point of view, approaching the triggers as separate factors, either physiological, affective or cognitive, may result in a narrow picture of information needs.

It should also be noted that the present study examined only one part of the discussion culture of dark Web marketplaces devoted to drugs. A major function of those sites is not the expression of needs, but rather information sharing. Sellers post information on what is available, at what price, and how safe the business transactions are supposed to be. Even though the sellers may not explicate these issues, they too have information needs. By writing that they have "drugs A, B, and C available, at prices X, Y and Z", they are signalling an information need: "who is my potential customer?", "who wants to buy what I have?", "will it be a safe trade?", and so forth. In future studies, it is also necessary to look into the information sharing practices taking place on sites such as Sipulitori, not just to understand information sharing there, but also the indirect expression of information needs.

\section{Conclusion}

This article explored the information needs of people using a Finnish dark Web marketplace to buy, sell and discuss the use of drugs. By looking at the highly drug-use related information needs of the users and the triggers for those needs, it has been possible to not only identify various needs that by nature appear to focus around the way of life of drug use, but also the ways in which a physiological need may lead to ongoing information seeking processes that are observable as individual instances of explicated need.

We have furthermore contributed to the understanding of drug trading and use in general. By understanding how the information needs on drugs are triggered by a combination of physical, affective and cognitive factors, it is possible to understand also drug seeking and purchasing behaviour. This illustrates the ways in which everyday information needs are intrinsically tied to 
human practices, and manifest in them. To understand the information needs of drug users is to understand the ways in which they think, and the ways in which they conduct their ways of life. The contents of their messages thus carry an importance far beyond just the interests of information scholars.

Most significantly, however, our findings show that information needs need to be examined more deeply than has been previously thought. Our findings suggest that Wilson (1981) and Taylor (1968) were already decades ago aware of how strongly information needs can be tied to physiological factors, whether we consider them as triggers vaguely recognized at the level of visceral needs or requests for information indicative of basic human needs such as need for food and shelter. At the same time, Taylor and Wilson showed that information needs may in fact be more complex than thought before. If hybrid triggers, such as we discuss here, indeed exist also elsewhere, it is necessary to look much more deeply into the root conditions of information needs and their formation.

\section{Funding}

This research did not receive any specific grant from funding agencies in the public, commercial, or not-for-profit sectors.

\section{References}

Agar, M. H. (1996). The professional stranger (Second edition). San Diego, CA: Academic Press.

Agosto, D. E. \& Hughes-Hassell, S. (2006). Toward a model of the everyday life information needs of urban teenagers. Part 2: empirical model. Journal of the American Society for Information Science and Technology, 57(11), 1418-1426.

Airaksinen, M., MacDonald, E., \& Korpi, E. R. (2014). Kannabiksen toleranssi ja vieroitusoireet. In O. Pelkonen \& H. Ruskoaho (Eds.), Lääketieteellinen farmakologia ja toksikologia (pp,674-705). 4. edition. Helsinki: Duodecim.

Bakken, S. A. \& Demant, J. J. (2019). Sellers' risk perceptions in public and private social media drug markets. International Journal of Drug Policy, Article Ahead of Print.

Barceloux, D.G. (2012): Medical toxicology of drug abuse. Synthesized chemicals and psychoactive plants. Hoboken, NJ: John Wiley \& Sons, Inc.

Bates, M.J. (2107). Information. In J.D. McDonald \& M. Levine-Clark (Eds.), Encyclopedia of library and information sciences (pp. 2048-2063) (Fourth Edition). London, UK: Taylor \& Francis.

Best, D., Beckwith, M., Haslam, C., Haslam, S.A., Jetten, J., Mawson, E., \& Lubman, D.I. 2016. Overcoming alcohol and other drug addiction as a process of social identity transition: the social identity model of recovery (SIMOR). Addiction Research \& Theory, 24(2), 111-123. https://doi.org/10.3109/16066359.2015.1075980.

Bicchieri, C., Muldoon, R., \& Sontuoso, M. (2018). Social norms. In Stanford encyclopedia of philosophy. Available at: https://plato.stanford.edu/entries/social-norms/ 
Bigdeli, Z. (2007). Iranian engineers' information needs and seeking habits: an agro-industry company experience. Information Research, 12(2). Available at: http://InformationR.net/ir/122/paper290.html.

Boyle, M.P., Schmierbach, M., Armstrong, C.L., McLeod, D.M., Shah, D.V., \& Pan, Z. (2004). Information seeking and emotional reactions to the September 11 terrorist attacks. Journalism \& Mass Communication Quarterly, 81(1), 155-167.

Burnett, G., Besant, M., \& Chatman, E.A. (2001). Small worlds: normative behavior in virtual communities and feminist bookselling. Journal of the American Society for Information Science and Technology, 52(7), 536-547.

Burnett, G., \& Buerkle, H. (2004). Information exchange in virtual communities: a comparative study. Journal of Computer-Mediated Communication, 9(2). Available at: http://jcmc.indiana.edu/vol9/issue2/burnett.html

Burnett, G., \& Jaeger, P.R. (2008). Small worlds, lifeworlds, and information: the ramifications of the information behaviour of social groups in public policy and the public sphere. Information Research, 13(2). Available at: http://InformationR.net/ir/13-2/paper346.html

Chatman, E.A. (1991). Life in a small world: applicability of gratification theory to informationseeking behavior. Journal of the American Society for Information Science, 42 (6), 438-449.

Chatman, E.A. (1992). The information world of retired women. Westport, Conn.: Greenwood Press.

Chatman, E.A. (1996). The impoverished life-world of outsiders. Journal of the American Society for Information Science, 47(3), 193-206.

Chatman, E.A. (1999). A theory of life in the round. Journal of the American Society for Information Science, 50(3), 207-217.

Chu, C.M. (1999). Literary critics at work and their information needs: a research-phases model. Library \& Information Science Research, 21(2), 247-273.

Cole, C. (2012). Information need. A theory connecting information search to knowledge formation. Medford, NJ: Information Today.

Cole, C. (2018). The consciousness' drive. Information need and the search for meaning. Cham, Switzerland: Springer.

Costello, K. L., Martin III, J. D., \& Edwards Brinegar, A. (2017). Online disclosure of illicit information: Information behaviors in two drug forums. Journal of the Association for Information Science and Technology, 68(10), 2439-2448.

Derr, R.L. (1983). A conceptual analysis of information need. Information Processing \& Management, 19(5), 273-278.

Dover, M. A., \& Joseph, B. H. R. (2008). Human needs: Overview. In T. Mizrahi \& L. Davis (Eds.), The encyclopedia of social work (20th ed., pp. 398-406). New York: Oxford University Press and National Association of Social Workers. 
Ferguson, R-H. (2017). Offline 'stranger' and online lurker: methods for an ethnography of illicit transactions on the darknet. Qualitative Research, 17(6), 683-698.

Fourie, I., \& Nesset, V. (2017). An exploratory review of research on cancer pain and informationrelated needs: what (little) we know. Information Research, 22(1). Available at: http://www.informationr.net/ir/22-1/isic/isic1621.html

Gehl, R. W. (2016). Power/freedom on the dark web: A digital ethnography of the Dark Web Social Network. New Media \& Society, 18(7), 1219-1235. https://doi.org/10.1177/1461444814554900.

Godbold, N. (2013). An information need for emotional cues: unpacking the role of emotions in sense making. Information Research, 18(1). Available at: http://InformationR.net/ir/181/paper561.html

Gorman, P. N. (1995). Information needs of physicians. Journal of the American Society for Information Science, 46(10), 729-736.

Haasio, A. (2015a). Disnormatiivinen ja normatiivinen informaatio. Informaatiotutkimus, 34(4). Available at: https://journal.fi/inf/article/view/53512.

Haasio, A. (2015b). Toiseus, tiedontarpeet ja tiedon jakaminen tietoverkon "pienessä maailmassa": tutkimus sosiaalisesti vetäytyneiden henkilöiden informaatiokäyttäytymisestä. Tampere, Finland: Tampere University Press (Acta Universitatis Tamperensis; 2082). Available at: https://tampub.uta.fi/bitstream/handle/10024/97938/978-951-44-9878-7.pdf?sequence=1

Haasio, A., Ojaranta, A., Mattila, M., \& Kannasto, E. (2018). Terrori-isku tiedontarpeiden virittäjänä: Turun puukotusten aiheuttamat tiedontarpeet. Informaatiotutkimus, 37(2). Available at: https://doi.org/10.23978/inf.71157

Harviainen, J. T., Haasio, A. \& Hämäläinen, L. (in press). Drug traders on a local dark web marketplace. In Encyclopedia of criminal activities and the deep web. Hershey, PA: IGI Global.

Hasler, L., Ruthven, I., \& Buchanan, S. (2014). Using Internet groups in situations of information poverty: topics and information needs. Journal of the Association for Information Science and Technology, 65(1), 25-36.

Helsingin Sanomat 1.11.2017. Tulli ja poliisi sulkivat suomalaisen huumekauppasivuston - ostajat ja myyjät siirtyivät oikopäätä kansainväliselle keskustelupalstalle. Available at: https:/www.hs.fi/kotimaa/art-2000005432007.html

Herman, E. (2004). Research in progress: some preliminary and key insights into the information needs of the contemporary academic researcher. Part 1. Aslib Proceedings, 56(1), 34-47.

Hersberger, J. (2001). Everyday information needs and information sources of homeless parents. The New Review of Information Behaviour Research, 2, 119-134.

Hyman, S. (2005). Addiction: a disease of learning and memory. American Journal of Psychiatry, 8, $1414-1422$. 
Julien, R. M., Advokat, C.D., \& Comaty, J.E. (2011). A primer of drug action. A comprehensive guide to the actions, uses and side effects of psychoactive drugs. New York: Worth Publishers.

Juric, M. (2017). The role of the need for cognition in the university students' reading behaviour. Information Research, 22(1). Available at: http://www.informationr.net/ir/22-1/isic/isic1620.html

Kalso, E. (2017). Opioiditoleranssi. In Pelkonen, O. \& Ruskoaho, H. Lääketieteellinen farmakologia ja toksikologia (Fourth edition). Helsinki: Duodecim.

Koob, G.F., Arends, M.A., \& Le Moal, M. (2014). Drugs, addiction, and the brain. San Diego: Elsevier Science Publishing Co, Inc.

Lapinski, M.K., \& Rimal, R.N. (2005). An explication of social norms. Communication Theory, 15(2), 127-147.

Lee, R.M. (1993). Doing research on sensitive topics. London: Sage.

Martin, J., \& Christin, N. (2016). Ethics in cryptomarket research. International Journal of Drug Policy, 35, 84-91.

Miranda, S.V., \& Tarapanoff, K.M.A. (2008). Information needs and information competencies: a case study of the off-site supervision of financial institutions of Brazil. Information Research, 13(2). Available at: http://InformationR.net/ir/13-2/paper344.html

Moyle, L., Childs, A., Coomber, R., \& Barratt, M. J. (2019). \#Drugsforsale: An exploration of the use of social media and encrypted messaging apps to supply and access drugs.

International Journal of Drug Policy, 63, 101-110.

National Advisory Board on Research Ethics (2009). Ethical principles of research in the humanities and social and behavioural sciences and proposals for ethical review (Finnish). Helsinki: National Advisory Board on Research Ethics.

Naumer, C.M. \& Fisher, K.E. (2017). Information needs. In J.D. McDonald \& M. Levine-Clark (Eds.), Encyclopedia of library and information sciences (pp. 2115-2121) (Fourth Edition). London, UK: Taylor \& Francis.

Nieborg, D. B., \& Helmond, A. (2018). The political economy of Facebook's platformization in the mobile ecosystem: Facebook Messenger as a platform instance. Media, Culture \& Society (forthcoming). https://doi.org/10.1177/0163443718818384

Nurmi, J., Kaskela, T., Perälä, J., \& Oksanen, A. (2017). Seller's reputation and capacity on the illicit drug markets: 11-month study on the Finnish version of the Silk Road. Drug \& Alcohol Dependence, 178, 201-207.

Petri, H.L., \& Govern, J.M. (2004). Motivation: theory, research and applications (Fifth edition) Belmont, CA: Wadsworth.

Rabina, D., Drabinski, E., \& Paradise, L. (2016). Information needs in prisons and jails: a discourse analytic approach. Libri, 66(4), 291-302. 
Ruthven, I. (2019). The language of information need: differentiating conscious and formalized information needs. Information Processing \& Management, 56(1), 77-90.

Ruthven, I., Buchanan, S., \& Jardine, C. (2018). Relationships, environment, health and development: the information needs expressed online by young first-time mothers. Journal of the Association for Information Science and Technology, 69(8), 685-695.

Savolainen, R. (1995). Everyday life information seeking: approaching information seeking in the context of way of life. Library \& Information Science Research, 17(3), 259-294

Savolainen, R. 2012. "Conceptualizing information need in context" Information Research, 17(4). Available at: Available at http://InformationR.net/ir/17-4/paper534.html

Savolainen, R. 2014. Emotions as motivators for information seeking: A conceptual analysis. Library \& Information Science Research, 36(1), 59-65. https://doi.org/10.1016/j.lisr.2013.10.004.

Savolainen, R. (2017). Information need as a trigger and driver of information seeking: a conceptual analysis. Aslib Journal of Information Management, 69(1), 2-21. https://doi.org/10.1108/AJIM-082016-0139.

Shoham, S., \& Kaufman Strauss, S. (2008). Immigrants' information needs: their role in the absorption process. Information Research, 13(4). Available at: http://InformationR.net/ir/134/paper359.html

Sternberg, R.J. (2009). Cognitive psychology (Fifth edition). Belmont, CA: Wadsworth.

Taylor, R.S. (1968). Question-negotiation and information seeking in libraries. College \& Research Libraries, 29(3), 178-194.

Tesch, R. (1990). Qualitative research. Analysis types and software. London: Falmer Press.

Westbrook, L, (2008). Understanding crisis information needs in context: the case of intimate partner violence survivor. The Library Quarterly, 78(3), 237-261.

Westbrook, L. (2009). Information myths and intimate partner violence: sources, contexts and consequences. Journal of the American Society for Information Science and Technology, 60(4), 828836.

Wilson, T.D. (1981). On user studies and information needs. Journal of Documentation, 37(1), 3-15.

Wise, R.A., \& Koob, G.F. (2014). The development and maintenance of drug addiction. Neuropsychopharmacology, 39, 254-262. Available at: https://www.nature.com/articles/npp2013261\#ref44. 